\title{
ПЕРСПЕКТИВЫ ТРАНСФОРМАЦИИ РЕСУРСОВ ЗОЛОТА НА ТЁСОВСКОМ УЧАСТКЕ С УЧЕТОМ ПРОГНОЗНОЙ МОДЕЛИ ТРАНСФОРМАЦИИ РЕСУРСОВ ОЛЬХОВСКОГО УЧАСТКА ПАШИЙСКОЙ ПЛОЩАДИ
}

\author{
А.С. Борисов \\ Горный институт УрО РАН, г. Пермь
}

\begin{abstract}
Аннотация: В представленном материале обсуждаются проблемы, связанные с нетрадиционными формами нахождения золота на Пашийской площади, и возможности пересчета прогнозных ресурсов нескольких перспективных участков. Ранее на Ольховском участке было проведено геологическое картирование и опробование, выделены основные проблемы методов анализа золота в нетрадиционных формах нахождения и подсчета ресурсной базы, проведена ревизия проб с последующим анализом нескольких представительных проб новым методом, учитывающим специфику золота, связанного с органическими соединениями, и его потерю при анализе проб традиционными методами. Результаты анализов показали увеличение содержания золота в проанализированных пробах как с ранее выделенными балансовыми содержаниями, так и, что наиболее важно, с забалансовыми содержаниями. На основе полученных результатов был составлен прогнозный пересчет ресурсной базы. Применение нового метода позволило осуществить прогнозную трансформацию ресурсов золота на Ольховском участке Пашийской площади.

Положительные прогнозные перспективы трансформации золота, связанного с органическими соединениями на Ольховском участке, позволили применить данную прогнозную модель трансформации ресурсной базы на Тесовском участке Пашийской площади.

Породы участка сложены доломитизированными известняками турнейского яруса, перекрываемыми аргиллитами, алевролитами и песчаниками западноуральской свиты визейского яруса нижнего карбона с признаками тектоно-гидротермальной активизации. Эти породы содержат концентрации золота, связанного с полиметальной минерализацией и органическими соединениями.

Ключевые слова: доломитизированные известняки, алевролиты, песчаники, аргиллизация, коры выветривания, тектоно-гидротермальная активизация, методология исследований, формы нахождения золота, пробирно-масс-спектрометрический метод с подшихтовкой хлоридами, трансформация ресурсов.
\end{abstract}

\section{Введение}

Перспективные на золото участки находятся в Пермском крае, на территории Горнозаводского района, севернее поселка Пашия. Тесовский участок расположен западнее Ольховского участка, между Тесовским и Зыковским надвигами, представляет собой грабен-синклиналь, в мульде которой выходят доломитизированные известняки турнейского яруса, перекрываемые аргиллитами, алевролитами и песчаниками западноуральской свиты визейского яруса нижнего карбона. Грабен-синклиналь со всех сторон окружена девонскими отложениями (Рис. 1). В породах Тесовского участка и Пашийской площади в целом проявлена Пермская тектоно-гидротермальная активизация. Вмещающие породы в той или иной степени аргиллизированы, вследствие чего происходило перераспределение концентраций золота и органического вещества. Характерной особенностью является высокое содержание органического вещества. Опробование площади Тесовского участка проводилось скважинами. В ходе бурения было отобрано и проанализировано 395 проб.

Скважинами вскрыты крутопадающие зоны мощностью от 5 до 60 м тёмно-серых до чёрного углисто-слюдисто-глинистых аргиллизитов с останцами, разрушенными до щебня, и глыб вмещающих пород. Зоны аргиллизитов сопровождаются участками дроблёных пород мощностью 10-30 м в обе стороны от жил. По данным рентгенофазового анализа аргиллизиты состоят из кварца, каолина, слюды, пирита и органического 
вещества, встречаются цеолиты и анатаз. Органическое вещество представлено преимущественно миграционным битуминозным веществом, сильно пиритизированным, смолистого состава (Табл. 1).

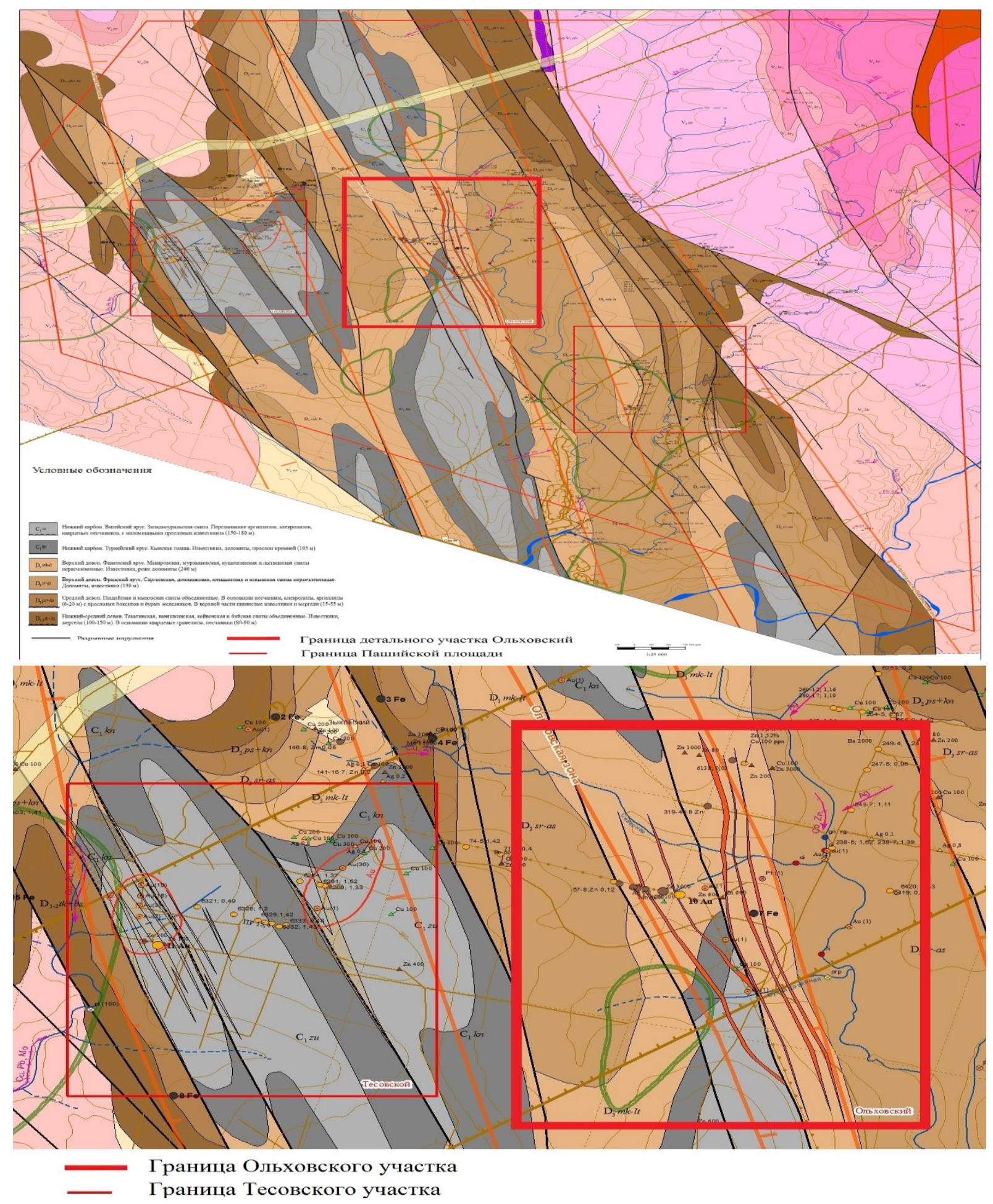

Рис. 1. Расположение Тесовского участка

Сульфидная минерализация приурочена к аргиллизитам и практически отсутствует в песчаниках и корах выветривания по ним. В верхней части, до глубины 30 м, располагается зона сульфидного выщелачивания, где сульфиды также не наблюдаются. Золото 
присутствует во всех пробах с содержаниями 0,2 г/т, по данным атомноабсорбционного анализа. По участку выполнен 41 пробирный анализ с шерберной плавкой, содержания золота составили $0,32-4,29$ г/т, в среднем - 1,55 г/т. Как установлено по результатам атомно-эмиссионного с индуктивно связанной плазмой и массспектрального с индуктивно связанной плазмой анализов, помимо пирита золото содержится в битуминизированных зёрнах кварца, зёрнах кальцита из карбонатных брекчий и в углеродисто-слюдисто-глинистом матриксе. Основной баланс золота связан с органическим веществом.

Таблица 1

\section{Характеристика органического вещества в породах Тесовского участка}

\begin{tabular}{|c|c|c|c|c|c|}
\hline Скв & $\begin{array}{c}\text { Глуб, } \\
\mathbf{M}\end{array}$ & $\begin{array}{c}\text { Микропетрографическая } \\
\text { характеристика }\end{array}$ & $\begin{array}{c}\text { Содержание } \\
\text { хлороформен- } \\
\text { ного битумо- } \\
\text { ида, } \\
\text { \% на породу }\end{array}$ & $\begin{array}{c}\text { Содержание } \\
\text { спиртобен- } \\
\text { зольного би- } \\
\text { тумоида, \% на } \\
\text { породу }\end{array}$ & $\begin{array}{c}\text { Содержа- } \\
\text { ние гуми- } \\
\text { новых } \\
\text { кислот, \% } \\
\text { на породу }\end{array}$ \\
\hline 307 & 109 & $\begin{array}{l}\text { Песчаник разнозернистый сидеритизи- } \\
\text { рованный с примазками желтовато- } \\
\text { бурого (иногда черного) битуминозного } \\
\text { вещества в межзерновом пространстве } \\
\text { наблюдаются единичные включения } \\
\text { колломорфного гумусового ОВ прихот- } \\
\text { ливых очертаний. С мелкими зернами } \\
\text { пирита по битуминозному веществу. }\end{array}$ & 0,08 & 0,0006 \\
\hline
\end{tabular}

Состав органического вещества отвечает сапропелевому типу (табл. 1.), как и в породах Ольховского участка (использованы данные ПГСП «Геокарта»). Анализы ОВ выполнены в лаборатории ГГР ГИ УрО РАН, Бачурин Б.А. (Горный ин-т УрО РАН, г. Пермь). По аналогии с результатами исследований по Ольховскому участку можно предположить, что часть золота может быть связана с органическим веществом, и это возможно большая часть концентраций золота (Сметанников, Серебряный, Красноштейн 2009; Сметанников, Седых 2016). Концентрации золота, связанные с органическими соединениями, не могут быть проанализированы традиционными аналитическими методами, поскольку ряд операций, связанных с разложением пробы (обжиг, выпаривание и др.), приводят к отжигу органики и уходу золота в возгоны (Плаксин И.Н., Опробование и пробирный анализ, М., 1947)). В конечном счете это приводит к полной потере золота, связанного с органическими соединениями. Исходя из этих соображений для Тесовского перспективного участка была применена прогнозная модель пересчета ресурсов с учетом использования метода ПМС с подшихтовкой хлоридами, использованная для Ольховского участка Пашийской площади.

\section{Методология исследований}

Поскольку рудовмещающие породы содержат значительные количества органического вещества, исходя из сведений о связи части благородных металлов с органическим веществом, были предприняты исследования большого количества проб, уже проанализированных вышеуказанными методами - шерберным (пробирным) методом с атомно-абсорбционным окончанием. При подготовке к анализу проба, смешанная с окисью свинца, покрывается слоем буры и фольгой. Этот прием препятствует уходу части золота в возгоны и анализ показывает более высокие содержания. 
Пробирным анализом с шерберной плавкой и атомно-абсорбционным окончанием была проанализирована 41 проба по поисковым скважинам и 4 пробы по картировочным, были уверенно получены содержания 1 г/т и выше, среднее содержание золота по ним составляет 1,55 г/т и 3,42 г/т, соответственно.

Результаты показали, что содержания золота в уже проанализированных вышеуказанными методами пробах на 2-3 раза превышают полученные ранее содержания.

На основе результатов анализа проб этим методом был произведен прогнозный подсчет ресурсов золота на Ольховском участке.

Для сравнения был применен новый метод - пробирно-масс-спектрометрический с подшихтовкой хлоридами, который показал еще более высокие результаты (табл. 2).

Как видно из табличных данных, определение содержания золота этим методом в 25 раз превышает содержания, полученные при помощи шерберного метода.

Определение содержания Аи методами: Пробирный анализ Таблица 2 с щерберной плавкой и атомно-абсорбционным окончанием (ПШ с ААС окончанием), Пробирно-масс-спектрометрический (ПМС) с подшихтовкой хлоридами

\begin{tabular}{|l|c|c|c|}
\hline \multirow{2}{*}{ Состав } & \multirow{2}{*}{ № пробы } & \multicolumn{2}{|c|}{ Методы анализа } \\
\cline { 3 - 4 } & $\begin{array}{c}\text { ПШ с ААС } \\
\text { окончанием }\end{array}$ & $\begin{array}{c}\text { ПМС с подшихтовкой } \\
\text { хлоридами }\end{array}$ \\
\hline $\begin{array}{l}\text { Алевролиты и биту- } \\
\text { минозные известняки }\end{array}$ & $319-79$ & 1,76 & 3,1 \\
\hline Коры выветривания & $50-8$ & 0,85 & 4,76 \\
\hline
\end{tabular}

\section{Результаты исследований}

На основе полученных результатов появилась возможность сделать пересчет результатов анализа проб, проанализированных ПШ с АAC, до прогнозных содержаний в этих же пробах, проанализированных ПМС методом с подшихтовкой хлоридами (Табл.3).

Это позволило составить прогнозный подсчет ресурсов по данным прогнозного пересчета анализа проб методом ПМС с подшихтовкой.

Таблица 3

Пример прогнозного пересчета результатов ПШ с ААС до содержаний, полученных при анализе этих же проб методом ПМС с подшихтовкой хлоридами

\begin{tabular}{|c|c|c|c|c|c|}
\hline \multirow{2}{*}{ Состав } & \multirow{2}{*}{ № пробы } & \multicolumn{2}{|c|}{$\begin{array}{c}\text { Инт. Опробования, } \\
\text { ПШ с }\end{array}$} & $\begin{array}{c}\text { ПМС с подших- } \\
\text { ААС }\end{array}$ \\
\cline { 3 - 4 } & & От & До & Хой хлоридами \\
\hline Песчаник & $307-106$ & 105,0 & 106,0 & 1,98 & 3,52 \\
\hline $\begin{array}{c}\text { Аргиллизит } \\
\text { с обломками } \\
\text { песчаника }\end{array}$ & $307-56$ & 55,0 & 56,0 & 2,44 & 4,34 \\
\hline Коры & $307-7$ & 1,0 & 4,0 & 4,0 & 22,4 \\
\hline Коры & $308-10$ & 7,0 & 10,0 & 2,0 & 11,2 \\
\hline
\end{tabular}


롭
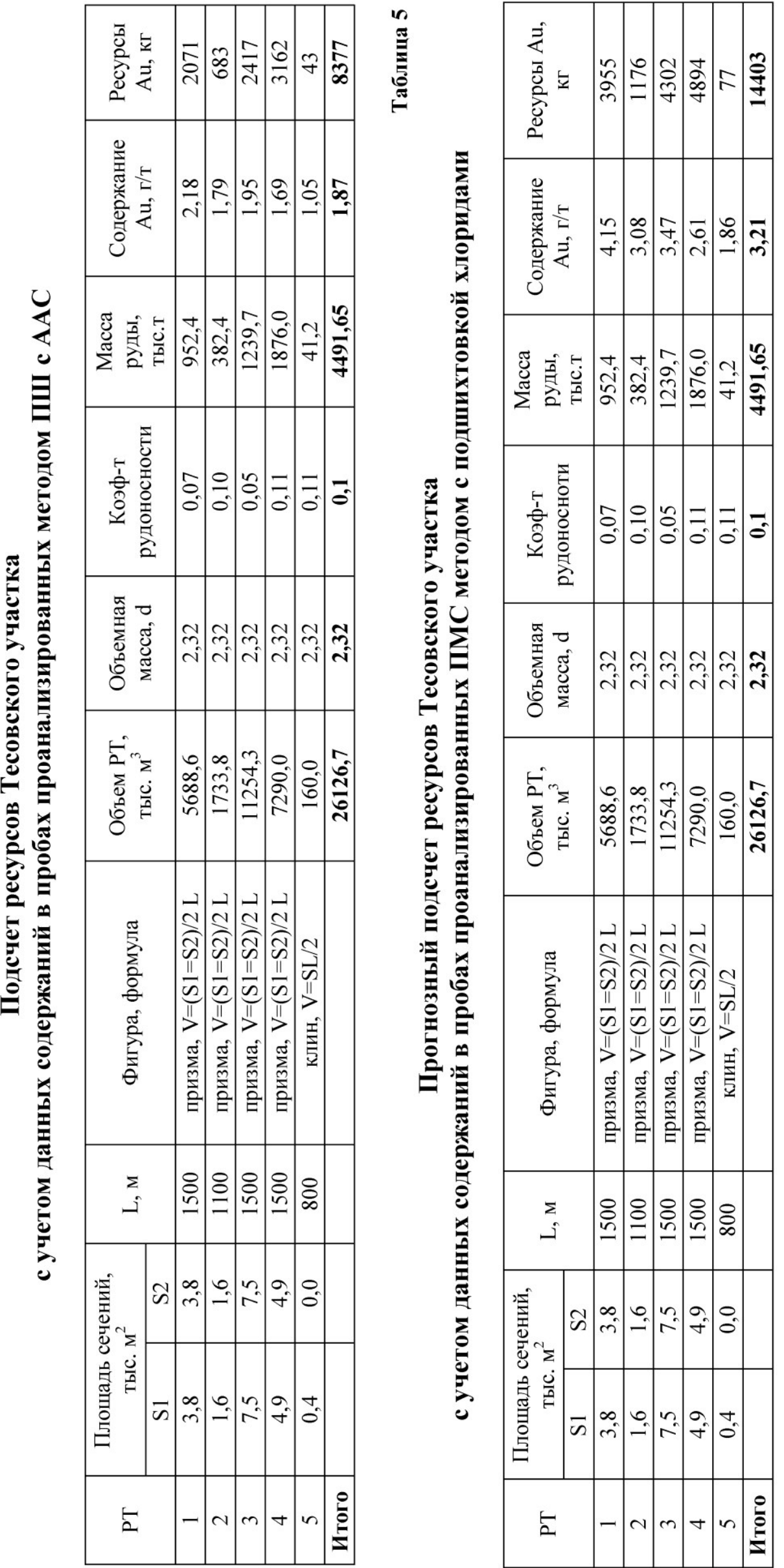
После прогнозного пересчета в пробах, проанализированных ПШ с АAC окончанием по поисковым скважинам, показано увеличение содержания золота на $40-50 \%$.

Полученные результаты вынесены на геологические разрезы для прогнозного пересчета и пересмотра поставленных на баланс ресурсов.

С учетом использования новых аналитических данных был произведен прогнозный пересчет ресурсной базы Ольховского перспективного участка и получен значимый прирост баланса ресурсов [1,2].

\section{Возможность трансформации ресурсов золота}

Далее приведены результаты прогнозного подсчета Тесовского участка. Прогнозный пересчет ресурсов проводился с учетом данных содержаний золота в пробах, проанализированных методом пробирного анализа с шерберной плавкой и атомноабсорбционным окончанием (табл. 4.) и с учетом прогнозных данных по содержаниям золота в этих же пробах, проанализированных методом ПМС с шихтовкой хлоридами (табл. 5.).

\section{Заключение и рекомендации}

1. Применение модели прогнозного пересчета ресурсов на базе пробирно-массспектрометрического метода с подшихтовкой хлоридами показывает возможный прирост баланса ресурсов золота на Тесовском участке за счет сохранения в анализируемых пробах части золота, связанного с органическим веществом.

2. Наиболее важным направлением дальнейших исследований на Тесовском участке, как и на Ольховском, является проведение анализа проб, проанализированных шерберным методом - пробирно-масс-спектрометрическим методом подшихтовкой хлоридами, - для полного подтверждения перспективности трансформации ресурсов и в дальнейшем выхода на работы, связанные с подсчетом запасов по Ольховскому участку и Тесовскому участку.

3. Анализ большего количества перспективных проб по бортам рудных тел исследуемых участков может расширить площадь исследуемых объектов, а значит увеличить ресурсную базу перспективных участков.

\section{Исследование выполнено в рамках Программь ФНИ, проект № 0422-2019-0144-C-02}

\section{БИБЛИОГРАФИЧЕСКИЙ СПИСОК}

1. Борисов А.С., Сметанников А.Ф., Суслов С.Б., Филатов А.В., Рыжов А.А, Петухов С.Н., Рыбьякова Н.М., Некрасов Д.И. Особенности распределения золота в известковисто-терригенных комплексах пашийской перспективной площади на западном склоне Урала (Ольховский участок) // Проблемы минералогии, петрографии и металлогении: науч. чтения памяти П.Н. Чирвинского / ПГНИУ [и др.]. - Пермь, 2018. - Вып. 21. - С. 247-252.

2. Борисов А.С. Перспективы трансформации ресурсов золота на Ольховском участке Пашийской площади с учетом новых аналитических данных по балансу золота, связанного с органическими соединениями // Горное эхо. - 2019. - № 3 (76). - C. 2-5. DOI: 10.7242/echo.2019.3.1.

3. Способ качественного и количественного определения органических соединений благородных металлов в породах различного состава: пат. № 2354967 Рос. Федерация: МПК G 01 N 30/06 (2006.01)/ Сметанников А.Ф., Серебряный Б.Л., Красноштейн А.Е; заявитель и патентообладатель ЗАО «Уралкалий-Технология». - № 2007134762/28; заявл. 18.09.2007; опубл. 10.05.2009. Бюл. № 13.

4. Сметанников А.Ф. Особенности анализа золота, связанного с органическими соединениями / А.Ф. Сметанников, Э.М. Седых // XXI Международная Черняевская конференция по химии, аналитике и технологии платиновых металлов: тез. докл. - Екатеринбург, 2016. - С. 61. 